\title{
PATHER and GPS Together to Improve Transport Efficiency
}

\author{
Ana Belén Pabón Dueñas \\ José Antonio Vera López \\ Roberto José Liñán Ruiz \\ University of Cordoba \\ Salvador Merino Córdoba \\ University of Malaga
}

\begin{abstract}
The new PATHER system becomes the perfect partner of GPS, so that the user gets a real positioning system when this is needed. This also includes positioning inside buildings. PATHER is based on Techno-accessibility and takes the concept of transport a step ahead, until developing a set of actions and providing services, in order to increase user information.
\end{abstract}

Using this system provides each individual the opportunity to feel confident and independent, regardless of their physical condition, because the system is able to act in many situations providing the user information necessary for optimal transport.

\section{Keywords}

PATHER, GPS, PLC, Techno-accessibility, Indoor navigation, RFID, IoT, Smartphone, Smart buildings, Positioning system, Apps, transport.

\section{INTRODUCTION}

The Global Positioning System (GPS) is defined as, an external positioning system that facilitates the location information, velocity and time to users who are on the surface of the Earth. Until now, it's impossible that GPS waves access inside buildings, but when a group of researchers of three engineers, two $\mathrm{PhD}$ in mathematics and an industrial designer from Malaga and Cordoba University prototype a possible solution to a global indoor positioning problem. Used their knowledge and creativity to brainstorm a solution to the problem, which has been patented.

Thanks to the symbiosis of the GPS system with the new indoor positioning system PATHER, the location is accurate. PATHER combines existing technologies in a completely new way and it is designed to get the user's location inside buildings in real time with a suitable surety.

PATHER is based on Techno-accessibility and takes the concept of transport a step ahead, until developing a set of actions and providing services, in order to increase user information. The government of Spain with the support of Europe has provided means to encourage the 
promotion and development of the information society. The roadmap for the achievement of the objectives of the Digital Agenda for Europe from 2014 to 2020, and incorporates specific targets for the development of the economy and the digital society in Spain. Starting with performances in the hotel sector, after the good reception of the first call in 2014, a second program in 2015, which allows us to offer a free wireless quality service to customers from any accommodation and absorb the increase of mobile devices available are presented per person having a budget of 15.000.000 Euros. These signs point to the Pather system will have a great reception by society and may even have support by the state.

\section{PATHER AND GPS, A COMMON EXAMPLE}

Today it's unusual to leave home without consulting the most appropriate route, the distance, or the travel time to our destination. With the use of both positioning systems, the user gets a real-time positioning inside and outside buildings and thus the optimal path to your own specifications.

For example, imagine you are guided from home to the office of a manager of a large company where you have a meeting. You have the possibility to know at all times the estimated time of arrival at the meeting, It's really interesting. Even more when all this information can be obtained using a simple app, downloaded and installed on our Smartphone.

All the time we are more connected to networks and the Internet provides us the ability to store information in an infinity of topics, managing and providing information in an effective manner. It is very useful.

- Knowing the state of the traffic all the time (traffic jams, accidents, maintenance works).

- Crowded sites and queues at different points.

- 3D buildings plans, to offer alternative ways depending on accessibility.

- 3D layouts of buildings, to offer alternative routes depending on accessibility

Updating data continuously it offers the possibility of providing the end-user real information. PATHER contributes towards efficient, safe and intelligent transport in the present and future.

There are several existing methods and infrastructures associated in the system: electricity network, internet, web pages, Wi-Fi, GNU General Public License, Bluetooth, Radio Frequency Identification, computers and servers.

\section{COMMUNICATION TECHNOLOGY}

\subsection{Wireless local area networks (WLAN): Wi-Fi}


$\mathrm{Wi}-\mathrm{Fi}$ is a technology that allows electronic devices to connect to a wireless LAN (WLAN) network, developed in the IEEE Standards Association process under 802.11 family, mainly using the $2.4 \mathrm{GHz}(12 \mathrm{~cm}) \mathrm{UHF}$ and $5 \mathrm{GHz}(6 \mathrm{~cm}) \mathrm{SHF}$ ISM radio bands.

Whereas the first version of the 802.11 protocol was released in 1997, and provided up to 1 or $2 \mathrm{Mbit} / \mathrm{s}$ in link speeds. The standard IEEE 802.11ac was developed from 2011 through 2013 and approved in January 2014 provided up to $1 \mathrm{GHz}$.

\begin{tabular}{|c|c|}
\hline IEEE Standards & WLAN Specifications \\
\hline 802.11b & $11 \mathrm{Mbit} / \mathrm{s} ; 2,4 \mathrm{GHz}$ \\
\hline 802.11a & 54 Mbit/s; 5 GHz \\
\hline 802.11g & $54 \mathrm{Mbit} / \mathrm{s} ; 2,4 \mathrm{GHz}$ \\
\hline 802.11n & $600 \mathrm{Mbit} / \mathrm{s} ; 2,4 \mathrm{GHz}$ and $5 \mathrm{GHz}$ \\
\hline 802.11ac & 1 Gbit/s; 5 GHz \\
\hline
\end{tabular}

Table 1 - IEEE 802.11 standards family

The antennas are the key of the wireless devices, because they are responsible for sending or receiving electromagnetic waves with the data. The most important characteristics to be assessed when choosing the antennas are:

- Scope or intensity, that is, the straight line distance between two points.

- Size, essential to know if it fits in the location where you need to register.

- Temperature ranges to endure running, knowing if suitable for indoor or outdoor.

- Type of polarization (vertical or horizontal).

- Frequency (for Wi-Fi 2.4 GHz band ranging between 2,400 and 2,485 MHz).

- Gain or power, expressed in $\mathrm{dBi}$ by the manufacturer or in real $\mathrm{dBd}$.

The main components of any WIFI network are:

- Access Point: A device that allows us to communicate to all components of the network with the router. Each access point has a maximum range of 90 meters in closed environments. In open spaces could be extended three times.

- Network Card: Connect the user to the nearest access point.

- Router: Connects an Internet access point.

WLAN does not replace LAN, but rather complements it, allows users and devices to stay connected and enjoy full freedom of movement, always living in harmony both technologies and can share between them all kinds of information.

3.2 Wireless personal area networks (WPAN): Bluetooth, RFID and TAG

\subsubsection{Bluetooth}


Bluetooth is a global wireless communication standard that connects devices together over a certain distance. Think headset, speaker, PC and smartphone. It is built into PATHER beacons and connects the Internet of Things (IoT). Pather device uses radio waves link in the ISM band $2.4 \mathrm{GHz}$, instead of wires or cables to connect to a smartphone or gadget; it contains a tiny computer chip with a Bluetooth radio and software that makes it easy to connect. When two Bluetooth devices want to talk to each other, they need to pair. The network ranges from two to eight connected devices. When a network is established, Pather takes the role of the master while all the other devices act as slaves.

Pather includes Bluetooth 4.2 while providing a better user experience for their customers, it makes smart, secure and fast the wireless technology.

\subsubsection{RFID and TAGs}

Thanks to Radio- frequency identification (RFID), Pather can record the presence of objects using radio signals. To do this, it relies on RFID tags, a small transponders which combined radio receiver and transmitter. This technology allowing ubiquitous wireless tracking and sensing. In the form of passive RFID, it is widely deployed in billions of units each year. Active RFID, versions with their own power source enable sensing, real time location systems and machine-to-machine communication via wireless sensor networks.

The table show the electromagnetic spectrum in the range, in which RFID typically operates and also the tag uses it to communicate or to obtain power.

\begin{tabular}{|c|c|c|}
\hline Name & Frequency range & ISM frequencies \\
\hline $\begin{array}{l}\text { Lf } \\
\text { (Low frequency) }\end{array}$ & $30-300 \mathrm{kHz}$ & $<135 \mathrm{KHz}$ \\
\hline $\begin{array}{l}\text { Hf } \\
\text { (High frequency) }\end{array}$ & 3-30 MHz & $\begin{array}{l}\text { 6.78 MHz, } 13.56 \mathrm{MHz}, 27.125 \mathrm{MHz}, \\
\text { 40.680 MHZ }\end{array}$ \\
\hline $\begin{array}{l}\text { UHF } \\
\text { (Ultra-high frequency) }\end{array}$ & $300 \mathrm{MHz}-3 \mathrm{GHz}$ & 433.920 MHz, 869 MHz, 915 MHz \\
\hline Microwave & $>\mathbf{3 G H z}$ & 2.45 GHz, $5.8 \mathrm{GHz}, 24.125 \mathrm{GHz}$ \\
\hline
\end{tabular}

Table 2 - RFID frequency ranges

RFID enabling visions such as Smart buildings, adding clear value for consumers.

\section{PATHER OBJECT}

A network of electronic components, which purpose is to guide anyone through the inside of a building using a navigation system, forms the system. The infrastructure of this network is based on Wi-Fi devices under PLC (Power Line Communications) that plugged at each point of electric current, create a mesh of sufficiently accurate waves to triangulate the position of the mobile navigation device and precisely guide the user to your destination. 
The use of PLC can develop a private network navigation that sends data to a central server and this, at a time and through the same Wi-Fi network, to give in the mobile the spatial representation of the building and its current location.

\subsection{PATHER beacon design}

The beacon is formed by electronic components located at existing points of electric current, possessing a transmission-reception antenna Wi-Fi signal which detect the distance that a mobile device is located. Through PLC technology, these devices communicate with each other to form a private network that communicates the data to that central server, at the end of the power supply (electric power transformer station).

The server calculates the relative positions of the user and sets its precise location within the building model using multiple triangulations. From here the information about your location and position plane to the mobile device user is returned so that it knows its location, the route to follow or how long you have left to get to your destination.

Physically, this device is structured in a box that is inserted into each building power point, hidden by the lid the conventional electrical terminal is installed at this point, either a plug or switch. In each of these boxes the following circuits are integrated:

- A connection module to the mains that feeds and connects the PLC network, through which it communicates with the central server that controls all devices.

- A transmission-reception antenna Wi-Fi signal, which detects mobile users devices to determine the distance that is at a given time.

- A Bluetooth beacon, which communicates with each user, transmitting the position indicated by the central server.

- A range of LEDs that indicate the state in which are the various means of connection offered by each of these devices.

Optionally, in this box the following blocks with more specific functions is also included:

- An output via Ethernet, which is connected to the PLC that generated network, usually to access the central server from any device.

- RFID card reader which detects the movement of anything that incorporates an RFID tag identification, as a trolley for carrying luggage, cleaning, etc. including blind people who can carry a card in your clothes or stick, to receive accurate information on the way forward where there's no margin for error.

- A USB port allows to configure the device, for example to identify, provide initial spatial coordinates, etc.

\subsection{Functioning diagram}


Each Pather point is connected to the mains of a building and configured, so that its exact position is situated in relation to other parts of the network. It has a transmission-reception antenna signal to detect the access distance, which is a mobile device. Through the PLC these devices communicate with each other to form a private network that communicates the data to a central server at the bottom of the grid.

The server calculates the relative positions of the user and providing precise location within the building model using multiple triangulations. From here it returns information about its location and position level to the user's mobile device so that it knows its location, building plans, showing different points of interest, the route to follow or how much you have left to reach your destination calculated by the Dijkstra method.

For the electronic device to receive the signal, one must first download and install a simple app on the electronic device. The plans of the 3D buildings are owned by the same. Owners must develop these plans and transmit the data to a website. Also this system can incorporate Augmented reality and holography, both increasingly used.

\section{NUMERICAL ALGORITHM SOLVES}

We develop numerical algorithm solutions for a new positioning system using technoaccessibility inside closed spaces. The end user will be guided through a smartphone using images and/or voice and will allow you to know the possibilities offered by the facilities where you are situated in real time.

This system has been implemented using wxMaxima computer algebra programme, a free source code under the GNU General Public License (GPL), in order to properly locate the user in a spot inside the building or transport with this new technology.

The data processed under wxMaxima and can have a wide variety of functions such as: creating virtual 3Dmodels of building, situation within them and added services. All this is the key to user-level interaction.

\subsection{Calculation of coordinates}

In principle the problem of synchronism raised is resolved with a system of three equations with three variables, so that the transmitter and the receiver are synchronised.

It calculates the position of a user $\mathrm{P}(\mathrm{x}, \mathrm{y}, \mathrm{z})$ knowing the fixed position of the three points $\mathrm{P} 1(\mathrm{x} 1, \mathrm{y} 1, \mathrm{z} 1), \mathrm{P} 2(\mathrm{x} 2, \mathrm{y} 2, \mathrm{z} 2)$ and $\mathrm{P} 3(\mathrm{x} 3, \mathrm{y} 3, \mathrm{z} 3)$ where we put each Pather device, knowing also the real distance D1, D2 and D3. 


$$
\begin{aligned}
& a: D 1^{2}=\left(\begin{array}{ll}
x & x 1
\end{array}\right)^{2}+\left(\begin{array}{ll}
y & y 1
\end{array}\right)^{2}+\left(\begin{array}{ll}
z & z 1
\end{array}\right)^{2} \\
& b: D 2^{2}=\left(\begin{array}{lll}
x & x 2
\end{array}\right)^{2}+\left(\begin{array}{lll}
y & y 2
\end{array}\right)^{2}+\left(\begin{array}{ll}
z & z 2
\end{array}\right)^{2} \\
& c: D 3^{2}=\left(\begin{array}{lll}
x & x 3
\end{array}\right)^{2}+\left(\begin{array}{lll}
y & y 3
\end{array}\right)^{2}+\left(\begin{array}{ll}
z & z 3
\end{array}\right)^{2}
\end{aligned}
$$

Taking into account the distortion that the signal suffers according to the travel time, the wave speed, the temperature and the density through the means which the signal travels. It is necessary to make a series of corrections to the values obtained.

\subsubsection{Correction of the distortion}

We emit a signal and we receive another signal in a determined time interval, obtaining the value of the distances plus the added error. In the calculation of the coordinates, we take into account the existing distortion between the emitted signal and the one received. The disturbances in the transmission of electromagnetic signals limit the speed. One of the rules of differential uniform linear motion is:

$\mathrm{di}=\mathrm{t} * \mathrm{v} \hat{A} \pm \mathrm{A}$,

with $\mathrm{i}=1,2,3$

Where:

$\mathrm{t}=$ Difference of the clock in between points, i. e, the travel time of the signal.

$\mathrm{v}=$ Radio wave speed: that is given by the technology used, depending on the environment of the application.

$A=$ Distortion. Controlled error supported in theory, due to the temperature function, the air density and the noise.

To be able to control the alterations produced we compare the values obtained in the measurement with the actual values, the distances between fixed points already known Dd, De and Df.

This way you can get and intelligent system capable of correcting its alterations learning at all times from their mistakes.

$$
\begin{aligned}
& d: D d^{2}=\left(\begin{array}{lll}
x 2 & x 1
\end{array}\right)^{2}+\left(\begin{array}{lll}
y 2 & y 1
\end{array}\right)^{2}+\left(\begin{array}{ll}
z 2 & z 1
\end{array}\right)^{2} \\
& e: D e^{2}=\left(\begin{array}{lll}
x 3 & x 2
\end{array}\right)^{2}+\left(\begin{array}{lll}
y 3 & y 2
\end{array}\right)^{2}+\left(\begin{array}{ll}
z 3 & z 2
\end{array}\right)^{2} \\
& f: D f^{2}=\left(\begin{array}{lll}
x 3 & x 1
\end{array}\right)^{2}+\left(\begin{array}{lll}
y 3 & y 1
\end{array}\right)^{2}+\left(\begin{array}{ll}
z 3 & z 1
\end{array}\right)^{2}
\end{aligned}
$$

Solving the systems we get values [d,e,f]; Dd,De,Df]. So when the disturbances in the transmission are null, the values obtained are real.

With the system of equations presented and previously studied counteracting distortion, we obtain solutions to infinite equations. Where the positioning is more accurate than currently 
offered by the GPS, with an error less than ten centimeters.

\section{APPLICATIONS}

PATHER applications are endless, especially highlighting the distance calculation in real time. The implementation in public and private buildings with large area such as airports, hospitals, university campuses, among others or transports, are of special interest.

PATHER not only adds value to intelligent buildings but also agrees with the globalization of smart cities bringing benefits for society in general.

The importance of this system makes sense because of the many applications that can be given. Fifty developed cases have been used, applicable in either public or private buildings, on the following concepts:

- Guide anyone.

- Location of objects and people.

- Quality control, production, distribution.

- Stock control, automatic inventory, orders.

- Control of the family economy.

- Development of business competition.

- Data storage.

- Consumer information.

- Reduction of time and cost.

- Control of time.

- Promotion of social relations.

- Databases.

This adds an attraction to the building, encouraging customers to come to the establishments. It is a highly attractive and competitive offer in the market. Thanks to smart buildings where PATHER will install in the future it will make life easier.

\section{CONCLUSION}

This system contributes to the new technologies of communication and information and is intended for all audiences. Using this system provides each individual the opportunity to feel confident and independent, regardless of their physical condition, because the system is able to act in many situations providing the user of information optimal transport.

An important aspect of the use of PATHER is the way you interact with the end user. Taking advantage of the smartphone use is widespread, the success of this technology is secured, because users do not need to carry more objects or spend money on new devices. 
You can get real value positioning of any proposed system, correcting variation that occurs between the transmitted signal and the received.

The PATHER system is perfected and corrected continuously, getting a better refining each time, since the continuous learning makes each movement more precise. With the mathematical calculation and thanks to the wxMaxima application we get an improved performance by each user in the building, making the interaction as safe and smooth as possible. It is applicable to commercial surfaces, residential, industrial, social, administrative and institutional amongst others.

After its development and implementation, the horizon of the future system is exciting. Its scope covers a wide variety of applications and provides a variety of uses, as it already occurs with current GPS navigation systems outdoors. Some of these new applications will be presented as the culmination of its work.

\section{REFERENCIAS}

(1) Miyoshi, Y.; Tsukamoto, K.; Tsuru, M.; OIE, Y. (2011). Network-supported TCP rate control for high-speed power line communications environments. Simulation Modelling Practice and Theory, 19, 69-83.

(2) Galán, J.L.; Galán, M.A.; Padilla, Y.; Rodríguez, P. (2006). Análisis Vectorial. Formularios técnicos y científicos. Ejercicios y problemas resueltos. Madrid. Bellisco Ediciones. I.S.B.N. 84-96486-18-4.

(3) Villarreal Solano, A. (2012). Fiabilidad de la red eléctrica para la transmisión de datos en banda ancha. Generación Digital. ISSN:1909-9223.

(4) Martínez Ramos, C. (2009). Bases tecnológicas de la telemedicina. Redes de telecomunicación. PLC. Fibra óptica. Satélites. Generación Digital. ISSN:1989-5003.

(5) Carcelle, X. (2009). Power Line Communications In Practice. Norwood, MA, USA: Artech House.

(6) Ting-part So. A. (1999). Intelligent Building Systems. [Springer version]. Doi: 10.1007/978- 1-4615-5019-8.

(7) Guzmán, F.; Merino, S.; Alba, R. (2013). Domótica: gestión de la energía y gestión tecnica de edificios. Universidad de Málaga. ISBN 846165935x.

(8) Trivio. G. (2004). Una propuesta para la Arquitectura Informática del sistema de control de un edifico. Informes de la construcción. CSIC. Vol 56, n494. 106-115.

(9) Ponce.P (2011). Inteligencia Artificial con aplicaciones a la ingeniería. Marcombo. Barcelona. I.S.B.N.978-84-267-1706-1.

(10) Glover, B.; Bhatt, H. (2006). RFID Essentials. O'Reilly Media, Inc., ISBN 0-59600944-5, 59. 